\title{
Personality Traits, Motivation and Foreign Language Attainment
}

\author{
Wenxia Zhang \\ Department of Foreign Languages \& Literatures, Tsinghua University, China \\ Danli Su \\ Department of Foreign Languages \& Literatures, Tsinghua University, China \\ Meihua Liu \\ Department of Foreign Languages \& Literatures, Tsinghua University, China
}

\begin{abstract}
This paper reports on the results of a study of Chinese EFL learners' personality traits and motivation in relation to their contributions to achievement in English at the tertiary level. An 88-item survey involving 934 first-year undergraduate non-English majors revealed that: (1) the participants were generally moderately extroverted, moderately prone to become anxious and be influenced by social desirability. Nevertheless, the majority reported to be dependent and tender-minded; (2) the majority of the participants reported to be moderately motivated to learn English; (3) the personality traits were significantly related to all or many of the motivation measures; and (4) most of the personality and motivation scales were significantly correlated with the students' attainment in English, among which, language requirement, intrinsic motivation, psychoticism and lie were good predictors of the latter.
\end{abstract}

Index Terms - personality, motivation, foreign language attainment

\section{INTRODUCTION}

The interrelations of personality and SL/FL learning have been a particular focus for some years (Ehrman \& Oxford, 1995; Verhoeven \& Vermeer, 2002). As claimed by Dörnyei (2005, p. 29), personality factors are 'heavily implicated in the learning process in general and in SLA in particular'. Generally they can act as 'powerful modifying variables' (2005, p. 24) which 'shape the way people respond to their learning environment' (2005, p. 30). So has been motivation (Dörnyei, 2001, 2005; Gardner, 1985, Gardner \& MacIntyre, 1991; Liu, 2007; Tremblay \& Gardner, 1995). Situated in a Chinese EFL learning context, the present study aims to explore students' personality characteristics and motivation patterns with relation to their contributions to the learning of English.

\section{LITERATURE REVIEW}

\section{Personality traits}

Personality has long been a particular focus of interest in education because personality traits make a difference in how people learn and what they learn (McCaulley \& Natter, 1974; Myres \& Myres, 1980). Among numerous personality measures, the most commonly used in the field of language learning and teaching are the Myers-Briggs Type Indicator (MBTI) and the Eysenck Personality Questionnaire (EPQ) (Moody, 1988). The MBTI is designed to measure differences on four bi-polar scales: Extroversion-Introversion, Sensing-Intuition, Thinking-Feeling, and Judging-Perceiving (Moody, 1988). The 100-item EPQ was later reduced to include 48 items and measures four dimensions of a person's personality (Eysenck \& Eysenck, 1985): extroversion (E), neuroticism (N) (or emotionality), psychoticism (P) (or tough-mindedness). It also has a lie scale (L) to measure the extent to which respondents are influenced by social desirability in answering the questionnaire. An individual who scores high on extroversion (HE) is oriented towards the external world while an individual who is low on extroversion (LE) is withdrawn and more concerned with inner stages of mind. An individual who is high on neuroticism (HN) is more inclined to anxiety and fears. A person with a low score on neuroticism (LN) is psychologically well-balanced (or stable). A person who is high on psychoticism is relatively tough-minded, aggressive and cold, whereas, a person with a low score on the P scale tends to be dependent and tender-minded.

Eysenck and Eysenck predicted that 'it is generally true at all ages from about 13 or 14 upwards that introverts show superior academic attainment to extravert' $(1985$, p. 321). This prediction has been confirmed in educational psychology by a range of studies (Robinson, Gabriel \& Katchan, 1994; Smart, Elton \& Burnett, 1970). However, concerning SL/FL learning, mixed findings are revealed (Ely, 1986; Liu \& Zhang, 2011; Smart et al., 1970; Strong, 1984). For example, Robinson et al.'s (1994) study revealed a strong correlation between extroversion and certain aspects of language attainment. Individuals with high neuroticism $(\mathrm{N})$ and extroversion $(\mathrm{HN} / \mathrm{HE})$ scores did better on the oral tests than on 
the written tests when compared with participants with high neuroticism and low extroversion scores (HN/LE). Measuring risk-taking and sociability as the functions of extroversion of 75 learners of Spanish at the tertiary level, Ely (1986) found no correlation between extroversion and class participation or Spanish proficiency.

Carrell, Prince and Astika (1996) administered the MBTI to 76 Indonesian learners of English at the tertiary level to study their personality types and their academic performance. They found that the participants were evenly divided between Extraverts and Introverts, but mostly belonged to Sensing-Thinking-Judging types. Few direct relationships between learners' type preferences and their language performance were exposed.

Moreover, students of different disciplines may display varying personality patterns. In Moody's (1988) study, 561 students at all levels of French, German and Spanish answered the MBTI. In addition, language students were compared with three specific groups: students of science, engineering, and business, hoping to find what kinds of teaching problems might be expected when a more diverse group of students enrolled for the same language course in the same classroom. It was found that students appeared in all sixteen personality categories and that language students favored strongly Intuition, Introversion, Thinking and Perception. On the scale of Extroversion and Introversion, students of language and engineering were around the same, but huge differences existed in comparing science with business. Introverts dominated in science but Extraverts were in the majority in business. In terms of learning, science students favored written drills and written tests while business students preferred spontaneous activities in group discussion and communicative activities. Language and engineering students liked Intuition while their business peers preferred Sensing.

\section{Motivation}

Motivation is considered subjected to variation depending on situational and other factors. Gardner's (1985) socio-educational model of language learning distinguishes integrative motivation (wishing to integrate into the target culture) from instrumental motivation (desiring academic or work-related achievements). Similar to this is intrinsic (coming from within the individual) and extrinsic (coming from outside the individual) motivation advanced by Deci and Ryan's (1985). Ehrman, Leaver and Oxford (2003, p. 320) suggest that 'a student's total motivation is most frequently a combination of extrinsic and intrinsic motivation' and that it 'depends greatly on the context, people involved, and specific circumstances'. The link with other factors reflects the process model of motivation which sees motivation as a 'dynamic, ever-changing process' (Dörnyei, 2005, p. 66) as it interrelates with other variables such as personality, beliefs, attitudes and the learning setting. As such, these interrelations are crucial to an understanding of the individual language learner experience. Dörnyei (2005, p. 118) maintains that this paradigm shift on the 'doing-side of personality' has resulted in 'an increased convergence of the concepts of personality and motivation, as both are now seen as antecedents of behavior'.

Involving 170 university students who had studied French, Gardner, lalonde and Moorcroft's (1985) study exposed that individuals with high levels of language aptitude were simply more able to incorporate the material as it was presented, that individuals with the more positive affective predispositions worked harder to acquire the material and that they were more interested in it, and that participants high on integrative motivation learned faster than those who were low, and the rate of learning was more rapid under visual/written conditions as compared with aural/oral ones. 134 young adult learners of English at beginning and intermediate levels participated in Dörnyei's (1990) study of the components of motivation in foreign-language learning. Analyses of the motivation questionnaire revealed that (1) instrumental motives significantly contributed to motivation in FLL contexts and were particularly efficient in energizing learning up to an intermediate level, and (2) integrative motivation was associated with a higher level of language attainment than was instrumental motivation.

In addition to research on the role of integrative/intrinsic and instrumental/extrinsic motivation in SL/FL learning, more motivation types are advanced during the process of motivation research (Belmechri \& Hummel, 1998; Gao, Zhao, Cheng \& Zhou, 2003a, 2003b, 2004; Liu, 2007, 2009; Oxford \& Shearin, 1994; Yang, Liu \& Wu, 2010). Based on the questionnaires distributed to 93 high school students, Belmechri and Hummel (1998) identified the following types of motivation: travel, understanding school (instrumental), friendship, understanding, and career (instrumental). Similarly, after analyzing 202 questionnaires filled by Chinese undergraduate non-English majors, Liu (2007) identified three motivation types - integrative, instrumental, and travel motivation and found that motivation was positively correlated with the students' English proficiency. Gao et al.'s (2003a, 2003b, 2004) extensive research involved 2,278 participants from 30 Chinese universities who answered a battery of self-developed questionnaire, which revelaed that students with higher motivations of intrinsic interest, going abroad, individual development and information media made more efforts in their English learning, that the group "high" in social responsibility motivation made more efforts than the "middle" and "low" groups, and that students with higher immediate achievement motivation made less learning efforts. The research (2004) aslo uncovered seven motivation types: intrinsic interest, immediate achievement, learning situation, going abroad, social responsibility, individual development, and information medium, which were grouped into three categories - instrumental, cultural and situational by the researchers. More proficient EFL learners reported to have significantly more intrinsic interest; and less proficient EFL learners were significantly more driven by immediate achievement. Based on the findings, the researchers suggested that native-culture orientation be incorporated to the traditional motivation framework.

In general, these studies are consistent in revealing that motivation contributes to the learning of a SL/FL, that 
learners high on integrative/intrinsic motivation work harder and learn faster than those who are low, and that learners demonstrate diverse motivation patterns, which is largely supported by numerous empirical studies in various contexts (Gardner \& MacIntyre, 1991; Gardner, 2002; Clëment, Dörnyei, \& Noels, 1994; Dörnyei \& Clëment, 2002; Liu, 2007; Strong, 1984; Ushioda, 2006, 2007, 2008)

\section{RATIONALE FOR THE STUDY}

To conclude, for both personality and motivation, mixed findings have been revealed, which may be because the studies have often examined the roles of personality and motivation in SL/FL learning with a heterogeneous and/or small group of learners. The findings might be more definite with a large homogeneous sample. This, coupled with low correlations found in many studies, deserves continuous research on the issues, as claimed by Spolsky (2000). For this purpose, the present research attempts to investigate the interrelationships of personality traits and motivation and their roles in language learning. The following research questions are of particular interest:

(1) What are the personality characteristics of this EFL population with a homogeneous L1 background?

(2) What are the motivation patterns of this EFL population with a homogeneous L1 background?

(3) Is there any relationship between the students' personality traits, motivation, and their performance in English?

\section{RESEARCH DESIGN}

Participants. The participants were 934 (587 male and 347 female) first-year non-English majors from various disciplines such as Law, Engineering, Mechanics and Economics and Management at three universities in China. All were enrolled in credit-bearing and compulsory English courses offered by their universities. With an age range from 13 to 21 and an average age of 18.49 , the majority (451/48.3\%) of the participants aged 18, followed by the group aged 19 $(315 / 33.7 \%)$, and then came the groups aged $20(97 / 10.4 \%)$ and $17(53 / 5.7 \%)$. As the law of family planning was executed in early 1971, most of the participants were the only children in their families.

Instruments. For this study, students completed the 48-item Eysenck Personality Questionnaire (EPQ), the 40-item English Learning Motivation Scale (ELMS), and the background questionnaire. In addition, all of them took the placement test organized by their universities a week before the study started.

The Eysenck Personality Questionnaire (EPQ). The 48-item Eysenck Personality Questionnaire was used in the present study because this revised form proved to be more valid and reliable (Eysenck, Eysenck \& Barrett, 1985) and because it was easier to be executed. It aimed to measure four dimensions of the students' personality with 12 items for each: psychoticism (P) (or tough-mindedness), extroversion (E), neuroticism (N) (or emotionality), and lie (L). For this scale, each item had two choices - "No" and "Yes" with values of 1 to 2 assigned to them respectively.

English Learning Motivation Scale. The 40-item English Learning Motivation Scale (ELMS) was designed with reference to several sources (Ely, 1986; Noels, Clèment \& Pelletier, 2001; Schmidt \& Watanabe, 2002; Vandergrift, 2005) to measure six dimensions of motivation: motivation intensity or strength of motivation (SOM) (6 items), intrinsic motivation (IntrinM) (6 items), language requirement (LR) (1 item), instrumental motivation (InstruM) (11 items), integrative motivation (IntegM) (12 items), and interest in foreign languages and cultures (IFLC ) (4 items).

As reviewed in the literature, SL/FL learning motivation is a complex construct and involves various learning orientations such as intrinsic and extrinsic, instrumental and integrative orientations. To avoid redundancy and better fit the present situation, the present 40-item English Learning Motivation Scale (ELMS) was designed with reference to several sources (Ely, 1986; Noels et al., 2001; Schmidt \& Watanabe, 2001; Vandergrift, 2005) and aimed to measure six dimensions: motivation intensity, intrinsic motivation, language requirement, instrumental motivation, integrative motivation, and interest in foreign languages and cultures. It achieved a reliability score (Cronbach $a$ ) of .87 in the present study. It should be noted that extrinsic motivation was excluded from the present study because we found that the items used to measure extrinsic motivation were similar to those for instrumental motivation and language requirement after careful comparison and discussion.

Strength of motivation was included because students might not really study English hard even though they were motivated to learn the language for various reasons. The 6-item Strength of Motivation (SOM) ( $a=.67)$ used in Liu's (2009) study (which was adapted from Ely's (1986)) aimed to measure learners' motivation intensity. The 6-item Intrinsic Motivation (IntrinM) $(a=.79)$ was adopted from Schmidt \& Watanabe (2002) to tap to what degree learners were intrinsically motivated to learn English. The 1-item language Requirement was incorporated in the ELMS because it was a fact that at least one English course was required with credits at each university. Both the 11-item Instrumental Motivation (InstruM) $(a=.71)$ and the 12-item Integrative Motivation (IntegM) $(a=.85)$ were adopted from Vandergrift (2005) and Noels et al.'s (2001) studies with repetitious items deleted. These two subscales sought to explore to what extent learners were instrumentally and integratively motivated to learn English respectively. Finally, the 4-item Interest in Foreign Languages and Cultures (IFLC) $(a=.68)$ was adopted from Schmidt $\&$ Watanabe's $(2002)$ study to examine how learners were interested in foreign languages and cultures.

Preliminary statistical analyses revealed high internal consistency for the measures (see Table 1). 
TABLE 1:

CHARACTERISTICS OF INSTRUMENTS $(\mathrm{N}=934)$

\begin{tabular}{|l|l|l|l|}
\hline Name of the instrument & No. of items & Reliability & Mean item-total correlation $(\mathrm{p}=.01)$ \\
\hline $\mathrm{P}$ & 12 & .48 & .45 \\
\hline $\mathrm{E}$ & 12 & .78 & .76 \\
\hline $\mathrm{N}$ & 12 & .77 & .75 \\
\hline $\mathrm{L}$ & 12 & .63 & .61 \\
\hline SOM & 6 & .42 & .39 \\
\hline IntrinM & 6 & .78 & .75 \\
\hline InstruM & 11 & .68 & .65 \\
\hline IntegM & 11 & .84 & .82 \\
\hline IFLC & 4 & .68 & .61 \\
\hline ELMS & 40 & .87 & .86 \\
\hline
\end{tabular}

The Background Questionnaire. The background questionnaire aimed to gather the respondents' demographic information such as name, gender, department, university, and English-learning time.

Attainment in English. All the participants' scores in the placement test were collected as their attainment in English.

Procedure. All the first-year undergraduate non-English majors at each university took a placement test prior to the first week's formal teaching of the first 16-week term of an academic year. Thirty intact classes of them at three universities answered the survey in 25 minutes during a normal class session of the second week. Of 1121 collected questionnaires, 934 were complete for further statistical analyses.

Data analysis. All the survey data were processed using SPSS 13. For each measure, the mean, standard deviation, median, and mode were calculated to determine what personality characteristics and motivation patterns they had. Then, relationships among these measured scales and the students' performance in English were investigated in terms of correlation analyses and regression analyses.

\section{RESULTS AND Discussion}

\section{Personality characteristics}

\section{Statistical analyses of the four subscales}

To examine the participants' personality traits, the means, standard deviations, medians, and modes of the four scales of the EPQ were computed. When doing so, the researchers adjusted the values assigned to the alternatives of some items, as specified in Eysenck et al. (1985). The results are reported in Table 2.

TABLE 2:

PERSONALITY TRAITS OF THE PARTICIPANTS $(\mathrm{N}=934)$

\begin{tabular}{|l|l|l|l|l|l|}
\hline & Mean & Standard Deviation & Median & Mode & Range \\
\hline $\mathrm{P}$ & 14.56 & 1.80 & 14 & 14 & $12-22$ \\
\hline $\mathrm{E}$ & 18.97 & 3.08 & 19 & 19 & $12-24$ \\
\hline $\mathrm{N}$ & 18.15 & 3.04 & 18 & 20 & $12-24$ \\
\hline $\mathrm{L}$ & 17.69 & 2.36 & 18 & 18 & $12-24$ \\
\hline
\end{tabular}

Table 2 shows that the means for $\mathrm{P}, \mathrm{E}, \mathrm{N}$ and $\mathrm{L}$ were $14.56(\mathrm{SD}=1.8), 18.97(\mathrm{SD}=3.08), 18.15(\mathrm{SD}=18.15)$, and 17.69 ( $\mathrm{SD}=2.36$ ), respectively, all close to the scale midpoint 18 except the $\mathrm{P}$ mean. So did the median and mode for each scale which fell from 14 to 20 . All these suggest that most participants were moderate on E, N and L but moderate and even low on P, as found in Eysenck et al.'s (1985) study. Namely, the participants were moderately extroverted, moderately inclined to anxiety and fears, and moderately prone to be influenced by social desirability; meanwhile the majority tended to be dependent and tender-minded.

Moreover, as noted from Figure 1, most of P scores centered around 13 to 16, with 14 having the highest percentage, while scores were more or less evenly distributed on E, N and L, with 18 to 20 being the center. This further confirms the finding that the respondents were generally not predominantly striking on any dimension of the EPQ except on P, as found in Liu \& Zhang (2011). This is surprising in that they, as the only children in their families, were often expected to be spoiled and might demonstrate extremity in personality. By contrast, few of them were extremely extroverted or introverted, highly prone to become anxious and/or fearful, and easily influenced by the society they lived in. This might be attributed to the country's (both the government's and individuals') economic prosperity and enormous investment in educating the single-child generations, which involves learning to be sharing, helpful, and cooperative. Expectedly, more than $90 \%$ of the participants reported to be dependent and tender-minded, which was largely owing to the fact that they had been well looked after. 


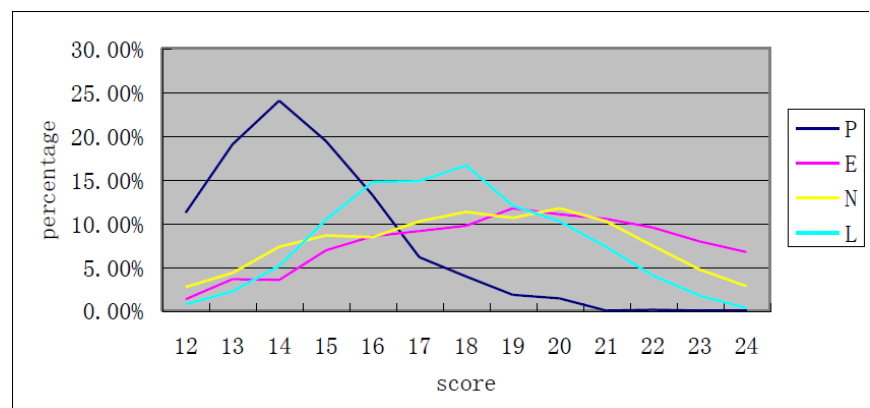

Figure 1: Distribution of Scores on P, E, N, and L

\section{Motivation pattern}

To reveal the general pattern of the students' English learning motivation, the means, standard deviations, medians, modes, maximums, and minimums of the ELMS and its subscales were computed. When doing so, the researchers adjusted the values assigned to the alternatives of items which expressed no motivation to learn English, as did with the EPQ. Thus, the total score of the ELMS revealed a respondent's general tendency of English learning motivation; so did the total scores of the ELMS subscales. And it holds true for all the measures that the higher the score, the more motivated the respondent was.

With 40 items, a score of more than 160 on the ELMS implies a strong motivation to learn English, a total score of 120 to 160 represents a moderate motivation, and a score of less than 120 signifies little motivation to learn the language. Likewise, a total score of more than 24 for the 6-item SOM or the 6-item IntrinM implies strong motivation strength or high intrinsic motivation, a total score of 18 to 24 implies moderate motivation strength or moderate intrinsic motivation, and a total score of less than 18 signifies low motivation strength or low/little intrinsic motivation. With only 1 item, a total score of more than 4, 3 to 4 and less than 3 for the LR indicates strong, moderate and low motivation of language requirement respectively. Similarly, a total score of more than 44, 33 to 44 and less than 33 for the 11 -item InstruM suggests high, moderate and low instrumental motivation respectively; a total score of more than 48,36 to 48 and less than 36 on the 12-item IntegM implies high, moderate and low integrative motivation respectively; and a total score of more than 16,12 to 16 and less than 16 on the 4-item IFLC suggests strong, moderate and low interest in foreign languages and cultures respectively. The higher the score, the more motivated the respondent reportedly was to learn English for various reasons. The results are presented in Table 3.

TABLE 3:

STATISTICAL ANALYSES OF THE ELMS AND ITS SUbSCALE $(\mathrm{N}=934)$

\begin{tabular}{|l|l|l|l|l|l|}
\hline Measures & Mean & Standard Deviation & Median & Mode & Range \\
\hline SOM & 22.16 & 3.89 & 22 & 22 & $6-30$ \\
\hline IntrinM & 19.19 & 4.58 & 19 & 18 & $6-30$ \\
\hline LR & 2.61 & 1.19 & 5.80 & 2 & 2 \\
\hline InstruM & 36.51 & 7.91 & 37 & 40 & $1-5$ \\
\hline IntegM & 36.63 & 2.81 & 37 & 37 & $15-55$ \\
\hline IFLC & 14.93 & 17.39 & 15 & 16 & $4-60$ \\
\hline ELMS & 132.03 & & 133 & 135 & $48-188$ \\
\hline
\end{tabular}

As shown in Table 3, the respondents achieved a mean of 132.03, a median of 133 and a mode of 135 on the ELMS, all above the scale midpoint 120, suggesting that the majority of them were moderately motivated to learn English, as found in Liu's (2007) and Yang and Lau's (2003) studies. This is, though surprising, reasonable in that all the participants were undergraduate non-English majors who inevitably gave priority to their major study. It might be also due to the fact that even though English had been receiving increasing attention in many fields in China, college students usually did not have much exposure to the language or contact with English-speaking people in their daily life, as claimed by Liu (2007).

Similarly, a mean of 22.16 on the SOM, 36.51 on the InstruM, and 14.93 on the IFLC respectively, coupled with their medians and modes which all well exceeded their scale midpoints, indicate that these learners had a moderate or even strong strength of motivation, were moderately or strongly instrumentally motivated, and were moderately or strongly interested in foreign languages and interacting with people from many cultures, consistent with the findings in Liu's (2007) study. As a global lingua franca, English has been attached increasing attention to in China and studied by Chinese learners with greater efforts. Meanwhile, as China knows more about the world, Chinese people have become more interested in knowing foreign languages and cultures. Understandably, they were fairly motivated to learn the language for various pragmatic reasons, as found in a range of other studies (Belmechri \& Hummel, 1998; Dörnyei, 2001; Gardner, 1985; Liu, 2007; Noels et al., 2001; Ushioda, 2007, 2008). To them, English was important in finding a good job, earning more money, receiving further education, passing exams, and so on.

In addition, a mean of 19.19, a median of 19 and mode of 18 on the IntrinM, all slightly above the scale midpoint 18 , show that the respondents were only moderately intrinsically motivated to learn English. They were moderately integratively motivated (mean $=36.63$ ) as well, contrary to Liu's (2007) but consistent with Lamb's (2004) (which 
studied integrative motivation of 219 Indonesian high school students) findings. To these learners, it was not a (high) priority to enjoy learning English and use it whenever having a chance. Nor would they have various feelings such as guilt, satisfaction and excitement in regard to English learning. All these might be because English, though important in certain ways, was still seldom used in their daily life.

Surprisingly, the students scored 2.61 on LR, with a median and mode of 2, all below the scale midpoint 3, implying that compulsory courses didn't constitute a great motivation for them to learn English.

Correlation between personality traits, motivation and attainment

Correlational analyses revealed the relationships between the students' personality traits, motivation and their attainment in English (see Table 4).

TABLE 4 :

CORRELATIONS AMONG PERSONALITY TRAITS, MOTIVATION AND ATTAINMENT

\begin{tabular}{|l|l|l|l|l|l|l|l|l|}
\hline & SOM & IntrinM & LR & InstruM & IntegM & IFLC & ELMS & Attainment \\
\hline $\mathrm{P}$ & $-.24 * *$ & $-.12^{* *}$ & $.12^{* *}$ & $-.09^{* *}$ & $-.12^{* *}$ & $-.19^{* *}$ & $-.19^{* *}$ & $-.12^{* *}$ \\
\hline $\mathrm{E}$ & $.08^{*}$ & $.25^{* *}$ & $-.09^{* *}$ & .03 & $.19^{* *}$ & $.19^{* *}$ & $.20^{* *}$ \\
\hline $\mathrm{N}$ & -.06 & $-.11^{* *}$ & $.12^{* *}$ & $.10^{* *}$ & .05 & -.03 & .02 \\
\hline $\mathrm{L}$ & $.10^{* *}$ & .06 & -.05 & $-.09^{* *}$ & .03 & .02 & .02 \\
\hline Attainment & $.16^{* *}$ & $.22^{* *}$ & $-.26^{* *}$ & -.04 & .02 & $-.02 * *$ \\
\hline
\end{tabular}

As shown in Table 4, P, E, N, L were significantly related to all or many of the motivation scales, with coefficients ranging from - .24 to .25 . A more toughed-minded person (higher on $\mathrm{P}$ ) tended to have weaker strength of motivation, be less intrinsically, instrumentally, or integratively motivated, be less interested in foreign languages and cultures, and be generally less motivated. On the contrary, a more extroverted student (higher on E) tended to be more motivated both intrinsically and integratively, be more interested in interacting with people from other cultures and have stronger motivation intensity. A participant who was more prone to become anxious (higher score on N) was more instrumentally but less intrinsically motivated. Finally, a student who reported to be more motivated by language requirement (LR) was more aggressive and tough-minded (higher on $\mathrm{P}$ ), more introverted (lower on E), and more prone to experience anxiety and fears (higher on $\mathrm{N}$ ).

Though personality traits and motivation were generally significantly interrelated, the correlations were not strong, which needs further research in other contexts. Hopefully, reasons for the low coefficients can be revealed.

Table 4 also shows that, all the measures except E, L, and InstruM were significantly correlated with the students' attainment in English. P, N, and LR were negatively while the others were positively related to the latter, with coefficients ranging from -.26 to .22 . It seems that a respondent who reported to be more tough-minded and aggressive (high on $\mathrm{P}$ ), easier to become anxious (high on $\mathrm{N}$ ), or more motivated by language requirement (high on LR) performed worse in English. Meanwhile, a participant who seemed to have stronger strength of motivation, be more intrinsically, instrumentally or integratively motivated, or be more interested in foreign languages and cultures tended to achieve more in English.

Similarly, it should be noted that the correlations between the measured variables and the students' attainment in English were low though significant. It might be because the latter was measured only by an overall performance score which included listening, reading and writing). The case might be different if the students' attainment in English had been measured in terms of speaking, listening, reading and writing. More personality traits and motivation scales would have been significantly correlated with some aspects of attainment in English and the coefficients might have been higher. All these need to be confirmed in future research.

\section{The regression model}

Correlational analyses exposed numerous bivariate relationships between personality traits, motivation and attainment in English, as previously discussed, but failed to reveal predictors of attainment in English. For this purpose, multiple regression analyses were conducted, which resulted in four models. A stepwise method was employed in forming regression models. The results are summarized in Table 5, which reports coefficients from the regression models, as well as their levels of significance.

TABLE 5:

REGRESSION COEFFICIENTS AND SIGNIFICANCE

REGRESSION COEFFICIENTS AND SIGNIFICANCE
\begin{tabular}{|l|l|l|l|l|l|}
\hline \multicolumn{2}{|c|}{} & LR & IntrinM & $\mathrm{P}$ & $\mathrm{L}$ \\
\hline \multirow{2}{*}{$\begin{array}{l}\text { Attainment } \\
\text { in English }\end{array}$} & $\beta$ & -.205 & .118 & -.085 & -.075 \\
\cline { 2 - 6 } & $t$ & -5.75 & 3.31 & -2.66 & -2.38 \\
\cline { 2 - 7 } & $\mathrm{p}$ & .000 & .001 & .008 & .018 \\
\hline
\end{tabular}

Table 5 shows that all the coefficients were statistically significant. Among the measured variables, four were included in the models in terms of achievement in English: LR was the most powerful predictor $(\beta=-.205, t=-5.75, \mathrm{p}$ $=.000)$, followed by IntrinM $(\beta=.118, t=3.31, \mathrm{p}=.001), \mathrm{P}(\beta=-.085, t=-2.66, \mathrm{p}=.008)$, and $\mathrm{L}(\beta=-.075, t=-2.38$, $\mathrm{p}=.018)$. Of the four predictors, only IntrinM was a positive one, all the others were negative ones.

Expectedly, intrinsic motivation contributed to achieving more in English, as found in numerous empirical studies 
(Clėment et al., 1994; Noels et al., 2001; Oxford \& Shearin, 1994). To our surprise, language requirement stipulated by the university not only failed to motivate the students to learn English, but hampered their learning of the language. Tough-mindedness and the propensity to be influenced appeared to be debilitators in learning English as well.

\section{CONCLUSIONS AND IMPLICATIONS}

Several conclusions concerning students' personality traits and motivation in relation to their roles in English learning in the Chinese EFL context are warranted from the results of this study.

Statistical analyses reveal that few extremes were found in terms of personality traits: the participants were generally moderate concerning extroversion-introversion, emotionality, and the influence of social desirability. Nevertheless, the majority reported to be dependent and tender-minded.

Concerning motivation, the majority of the participants again reported to be moderate. The learners generally did not work very hard at English, and were instrumentally motivated or interested in foreign languages and cultures to a certain degree which was well above the average but not strong enough. Their intrinsic and integrative motivation was even lower though also moderate. In addition, compulsory courses with credits failed to motivate the students as much as we had expected, which was probably because these students, as successful survivors of the National Matriculation Examinations, had come to the stage of learning for learning's sake instead of for fulfilling requirements.

With regard to the relation between the measured variables, extroversion $(\mathrm{E})$, neuroticism $(\mathrm{N})$, psychoticism $(\mathrm{P})$ and lie (L) were significantly related to all or many of the motivation scales. And most of the personality and motivation scales were significantly correlated with the students' attainment in English. However, only language requirement (LR), intrinsic motivation (IntrinM), psychoticism (P) and lie (L) were revealed to be good predictors of the latter.

As such, it may be useful to open seminars or training courses to guide students onto a track which may be more helpful to their education, life and career. As revealed in the present study, a person who is more extroverted tends to be more psychologically balanced; a more tough-minded person is less prone to be influenced by social desirability. Hence, intentional seminars and training may enable some students to self-consciously change their behavior and personality patterns, such as to become more outgoing and/or stronger. In this way, they may even become more motivated to learn a foreign language (e.g., English) as well, leading to better performance in the language.

At the same time, it may be ideal for EFL teachers to employ various teaching methods to cater to students with different personality traits. For example, more discussion activities can be designed for extroverted and psychologically balanced students, while introverts should also be encouraged to be more involved in speaking activities. Tough-minded learners can be more engaged in debates to learn to listen to and even cooperate with others, compromising themselves sometimes. Meanwhile, it is necessary to encourage students to utilize various learning strategies and styles which benefit them most according to their personality traits, as found in Ehrman and Oxford's (1995) study.

In addition, how to motivate students to learn the target language should always be a concern for EFL teachers and educators. As the world is becoming more and more globalized and English is more universally used in various fields, more and more Chinese learners are no longer or not strongly motivated to learn the language by passing exams or achieving high course grades (especially when nowadays it has become so easy to pass course exams in university). Instead, they work hard at the language may be because they want to know about foreign countries and cultures, to increase their professional knowledge, to enhance their self-value in the future job market, and so on. Thus, course designers of a university must take these changes or factors into consideration when stipulating compulsory foreign language courses. More content-based English medium courses may be more acceptable to university students who have already acquired the general knowledge of grammar and even reading, especially to those who are fairly proficient in English. Meantime, various optional courses can be offered at the tertiary level to cater to the needs to different students, aiming to maintain and further arouse students' interest in English and its culture, as claimed by Liu (2007). In the classroom, certain measures can also be taken to help enhance students' motivation to learn English. Since EFL learners in China often do not have enough contact with the target language or the target language community, teachers can enhance their exposure to it and give more input to promote their interest in learning the language and its culture (Dörnyei, 1990; Strong, 1984). EFL teachers can also provide positive competence feedback to increase learners' intrinsic motivation (Ramage, 1990).

\section{ACKNOWLEDGEMENT}

The present study was sponsored by Asia Research Center in Tsinghua University in 2010.

\section{REFERENCES}

[1] Belmechri, F., and Hummel, K. (1998). Orientations and motivation in the acquisition of English as a second language among high school students in Quebec city. Language Learning, 2, 219-244.

[2] Carrell, P. L., Prince, M. S., and Astika, G. G. (1996). Personality types and language learning in an EFL context. Language Learning, 46(1), 75-99.

[3] Clèment, R., Dörnyei, Z., and Noel, K. A. (1994). Motivation, self-confidence, and group cohesion in the foreign language. Language Learning, 3, 417-448. 
[4] Deci, L., and Ryan, M. (1985). Intrinsic motivation and self-determination in human behavior. New York: Plenum.

[5] Dörynei, Z. (1990). Conceptualizing motivation in foreign language learning. Language Learning, 40, 45-78.

[6] Dörnyei, Z. (2001). Teaching and researching motivation. Longman: Pearson Education Limited.

[7] Dörnyei, Z. (2005). The psychology of the language learner. Mahwah, NJ: Lawrence Erlbaum Associates.

[8] Dörnyei, Z., and Clement, R. (2002). Motivational characteristics of learning different target languages: results of a nationwide survey. In Z. Dörnyei, and R. Schmidt (Eds.), Motivation and second language acquisition (pp. 399-432). Honolulu: University of Hawaii Press.

[9] Ehrman, M. E., Leaver, B. L., and Oxford, R. L. (2003). A brief overview of individual differences in second language learning System, 31, 313-330.

[10] Ehrman, M. E., and Oxford, R. (1995). Cognition plus: correlates of language learning success. Modern Language Journal, 79, 67-89.

[11] Ely, C. M. (1986). Language learning motivation: A descriptive and causal analysis. Modern Language Journal, 70, $28-35$.

[12] Eysenck, H. J., and Eysenck, M. W. (1985). Personality and individual differences: a natural science approach. London: Plenum Press.

[13] Eysenck, S. B. G., Eysenck, H. J., and Barrett, P. (1985). A revised version of the psychoticism scale. Personality and Individual Differences, 6(1), 21-29.

[14] Gao, Y., Zhao, Y., Cheng, Y., and Zhou, Y. (2003a). The relationship between Chinese college undergraduates English learning motivational intensity and their self identity changes. Foreign Languages and Their Teaching, 170 (5), 25-28.

[15] Gao, Y., Zhao, Y., Cheng, Y., and Zhou, Y. (2003b). The relationship between types of English learning motivation and motivational intensity - a quantitative study on Chinese college undergraduates. Foreign Languages Research, 77 (1), 60-64.

[16] Gao, Y., Zhao, Y., Cheng, Y., and Zhou, Y. (2004). Motivation types of Chinese university undergraduates. Asian Journal of English Language Teaching, 14, 45-64.

[17] Gardner, R. C. (1985). Social psychology and second language learning: The role of attitudes and motivation. London: Arnold.

[18] Gardner, R. C. (2002). Integrative motivation and second language acquisition. In Z. Dörnyei, and R. Schmidt (Eds.), Motivation and second language acquisition (pp. 1-20). Honolulu: University of Hawaii Press.

[19] Gardner, R. C., Lalonde, R. N., and Moorcroft, R. (1985). The role of attitudes and motivation in second language learning: Correlational and experimental considerations. Language Learning, 1, 207-227.

[20] Gardner, R. C., and MacIntyre, P. D. (1991). An instrumental motivation in language study. Studies in Second Language Acquisition. 13, 57-72.

[21] Lamb, M. (2004). Integrative motivation in a globalizing world. System, 32, 3-19.

[22] Liu, M. (2007). Chinese students' motivation to learn English at the tertiary level. Asian EFL Journal, 9(1), 126-146.

[23] Liu, M. (2009). Reticence and anxiety in oral English lessons. Berne: Peter Lang.

[24] Liu, M., and Zhang, Z. (2011). An exploration of Chinese EFL learners' foreign language anxiety, personality and self-esteem. Journal of Applied Linguistics, 5(2), 181-203.

[25] McCaulley, M. H., and Natter, F. (1974). Psychological (Myres-Briggs) type differences in education. Gainesville, FL: Center for Applications of Psychological Type.

[26] Moody, R. (1988). Personality preferences and foreign language learning. Modern Language Journal, 72, 389-401.

[27] Myres, I. B., and Myres, P. B. (1980). Gifts differing. Palo Alto: Consulting Psychologists

[28] Noels, K. A., Clèment, R., and Pelletier, A. G. (2001). Intrinsic, extrinsic, and integrative orientations of French Canadian learners of English. The Canadian Language Review, 57, 424-442.

[29] Oxford, R., and Shearin, J. (1994). Language learning motivation: Expanding the theoretical framework. Modern Language Journal, 78, 12-27.

[30] Ramage, K. (1990). Motivational factors and persistence in foreign language study. Language Learning, 2, 189-219.

[31] Robinson, D., Gabriel, N., and Katchan, O. (1994). Personality and Second Language Learning. Personality and Individual Differences, 16(1), 143-157.

[32] Schmidt, R., and Watanabe, Y. (2002). Motivation, strategy use, and pedagogical preferences in foreign language learning. In Z. Dörnyei, and R. Schmidt (Eds.), Motivation and second language acquisition (pp. 313-359). Honolulu: University of Hawaii Press.

[33] Smart, J., Elton, C., and Burnett, C. (1970). Underachievers and overachievers in intermediate French. Modern Language Journal, 54, 415-420.

[34] Spolsky, B. (2000). Anniversary article: language motivation revisited. Applied Linguistics, 2, 157-169.

[35] Strong, M. (1984). Integrative motivation: Cause or result of successful second language acquisition. Language Learning, 1, $1-14$.

[36] Tremblay, P. F., and Gardner, R. C. (1995). Expanding the motivation construct in language learning. Modern Language Journal, 79, 505-518.

[37] Ushioda, E. (2006) Language motivation in a reconfigured Europe: access, identity, autonomy. Journal of Multilingual and Multicultural Development, 27(2): 148-161.

[38] Ushioda, E. (2007). Motivation and language. In J. Verschueren, J-O. Östman, and E. Versluys (Eds.), Handbook of pragmatics. Amsterdam: John Benjamins.

[39] Ushioda, E. (2008) Motivation and good language learners. In C. Griffiths (ed.), Lessons from good language learners (pp.19-34). Cambridge: Cambridge University Press.

[40] Vandergrift, L. (2005). Relationships among motivation orientations, metacognitive awareness and proficiency in L2 listening. Applied Linguistics, 26, 70-89.

[41] Verhoeven, L., and Vermeer, A. (2002). Communicative competence and personality dimensions in first and second language learners. Applied Psycholinguistics, 23, 361-374.

[42] Yang, A., \& Lau, L. (2003). Student attitudes to the learning of English at the secondary and tertiary level. System, 31 , 107-123.

[43] Yang, L., Liu, M., and Wu, W. (2010). An investigation of Chinese undergraduate Non-English majors' English learning 
motivation. In Zhongshe Lu, Wenxia Zhang, \& Paul Adams (eds.), ELT at tertiary level in Asian context: issues and researchers (pp. 48-62). Beijing: Tsinghua University.

Wenxia Zhang is professor of English at the Department of Foreign Languages \& Literatures, Tsinghua University, China. Her research interests mainly include EFL teaching and learning in the Chinese context, and language testing.

Danli Su is associate professor of English at the Department of Foreign Languages \& Literatures, Tsinghua University, China. She is mainly interested in language teaching and learning in Chinese contexts.

Meihua Liu is associate professor of English at the Department of Foreign Languages \& Literatures, Tsinghua University, China. Her research interests mainly include EFL teaching and learning in the Chinese context, reticence and anxiety, EFL writing, and study abroad. 